\title{
Determination of Permeability of Granitic Rocks in GT-2 from Hydraulic Fracturing Data
}

by

\author{
Georg Delisle*
}

*Participant in Dry Hot Rock Technology Project, NATO-CCMS Geothermal Energy Pilot Study, from the Federal Institute for Geosciences and Natural Resources, Federal Republic of Germany. 


\section{DISCLAIMER}

This report was prepared as an account of work sponsored by an agency of the United States Government. Neither the United States Government nor any agency Thereof, nor any of their employees, makes any warranty, express or implied, or assumes any legal liability or responsibility for the accuracy, completeness, or usefulness of any information, apparatus, product, or process disclosed, or represents that its use would not infringe privately owned rights. Reference herein to any specific commercial product, process, or service by trade name, trademark, manufacturer, or otherwise does not necessarily constitute or imply its endorsement, recommendation, or favoring by the United States Government or any agency thereof. The views and opinions of authors expressed herein do not necessarily state or reflect those of the United States Government or any agency thereof. 


\section{DISCLAIMER}

Portions of this document may be illegible in electronic image products. Images are produced from the best available original document. 
In the interest of prompt distribution, this report was not edited by the Technical Information staff.

primed in the l nited states of America. Available trom Salsiunal Technical Intormatiom Service

l'.s. Jepartment of Commerce

i2R: Port Roval Road

suringfield. VA 2.21:il

Price: Printed (op) \$4.50 Microliche \$2.25 
The Los Alamos Scientific Laboratory is currently conducting a study to determine the feasibility to extract geothermal energy from dry hot rock. The investigated concept calls for the creation of a hydraulic fracture in hot, impermeable rock. Heat will be exchanged subsequently at the fracture surface between the rock and a circulating flutd.

The successful creation of hydraulic fractures in the granitic section of exploratory holes GT-1 and GT-2 yielded sufficient data to calculate the average permeability of the rock next to a fracture by means of the mathematical model presented in this report. The calculated permeabilities were found to be in the microdarcy range and prove the granitic rock penetrated by GT- 1 and GT- 2 to be sufficiently impermeable to test the above concept.

\section{INTRODUCTION}

A research program to investigate the feasibility to extract geothermal energy from dry hot rock is presently being carried out by the Los Alamos Scientific Laboratory. The current efforts concentrate on the creation of a large fracture in a hot granitic body in the Jemez Mountains near Los Alamos, New Mexico. The fracture is intended to serve as a heat-exchanging surface when cool water is forced into the fracture. This concept requires that the rock from which heat will be extracted be essentially impermeable to limit the loss of water into the rock.

From the successful creation of several fractures in granitic rock in the boreholes GT-1 and GT-2, which served primarily for experimental purposes, sufficient data have been collected to permit the approximate determination of the in situ permeability of the rock prior to fracturing. For this purpose, a mathematical method, which takes into account the time dependence of the fracture growth and of the pore pressure buildup in the rock adjacent to the fracture, is presented below.

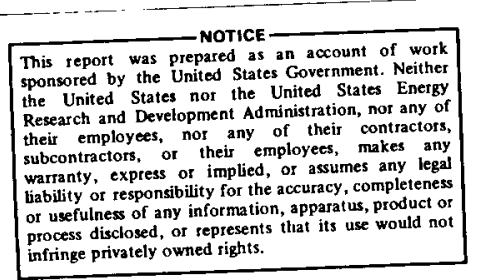

This mathematical method is applicable for cases where a constant flow rate of flutd into the opening fracture during the hydraulic-fracturing operation is maintained. The amount of fluid returning from the fracture upon venting must be accurately shown.

Furthermore, the method assumes that the necessary overpressure to maintain a constant flow rate has not changed significantly after fracture initiation. This effect has been observed in all hydraulic fracturing experiments in $\mathrm{GT}-1$ and $\mathrm{GT}-2$, which indicates that the fractured rock possesses a rather uniform permeability.

After fracture initiation, a constant flow rate of fluid into the fracture causes a growth and widening of the crack. The amount of newly created fracture surface per unit of time depends on the fluid flow rate minus the quantity of fluid which penetrates into the rock. We assume in this mathematical model that an idealized, Sneddon ${ }^{1}$-Sack, ${ }^{2}$ penny-shaped fracture is created whose radius $R$ is given by an equation proposed by Aamodt ${ }^{3}$ 
$R=757.5\left[\frac{Q_{r} t}{37.85}\right]^{0.4}[\mathrm{~cm}]$,

where:

$t=t i m e, s e c$

$Q_{r}=f l u l d-f l o w$ rate minus fluid-loss rate into rock, liters/sec.

The surface area of the fracture can be calculated as

$A \simeq 5.74 \times 10^{5} \pi\left(\frac{Q_{r} t}{37.85}\right)^{0.8} \quad\left[\mathrm{~cm}^{2}\right]$.

As a fresh fracture surface is generated, water will penetrate the rock immediately, due to the waterpressure gradient between the fracture and the rock. The water-pressure distribution in the rock next to the fracture as a function of distance and time is given by

$P(x, t)=P_{0}+\Delta P \operatorname{erfc}\left(\frac{x}{2 \sqrt{\nu t}}\right) \quad[$ bars $]$,

assuming one-dimensional, laminar flow through an isotropic, porous medium perpendicular to the faces of the fracture, where:

$P_{0}=$ pore fluid pressure existing in rock prior to fracturing, bars;

$\Delta P=$ overpressure applied during fracturing, bars;

$x=$ distance from fracture, $\mathrm{cm}$;

$\nu=\frac{\mathrm{k}}{\mu \mathrm{c} \phi}=$ hydraulic diffusivity, $\mathrm{cm}^{2} / \mathrm{sec}$;

$\mathrm{k}=$ permeability of rock, darcys or $\mathrm{cm}^{2}$;

$\mu=$ viscosity of water, centipoise $(0.01 \mathrm{~g} / \mathrm{cm}-\mathrm{sec})$;

$c$ = mean compressibility of rock and water combined, bars ${ }^{-1}$ or $\left(\text { dynes } / \mathrm{cm}^{2}\right)^{-1}$;

$\phi=$ porosity of rock.

The velocity of water penetrating the rock is given by Darcy's law:

$V=\frac{k}{\mu} \frac{\partial P}{\partial x}$

At the fracture-water interface, $x=0$, the velocity of water is obtained by combining Eqs. (3) and (4)

$v_{o}=\frac{\Delta P \sqrt{c \phi k}}{\sqrt{\pi \mu t}} \quad[\mathrm{~cm} / \mathrm{sec}]$
The total amount $Q$ of water lost from the fracture into the rock for any area $A$ is given by

$Q=2 \int_{0}^{t} A v_{0} d t \quad\left[\mathrm{~cm}^{3} / \mathrm{sec}\right]$

where $V_{0}$ is the penetration rate of water at the interface $x=0$ and $t_{1}$ is the time which elapsed between opening of the area $A$ by hydraulic fracturing and venting of the crack. As venting occurs it can be expected that some of the water forced into the pore spaces of the rock during fracturing will flow back into the fracture due to the reversal of the pressure gradient. However, the return flow of water within a closing fracture is a much more efficient process than the removal of pore fluids from nearly impermeable rock through a rapidly closing fracture into the borehole. Consequently, the amount of returning water after venting, subtracted from the volume of fluid forced into the opening crack, gives a fairly accurate estimate of the quantity of water that has penetrated into the rock. Figure 1 shows the history of a pressurization experiment in Zone 7 $6600 \mathrm{ft}$ ( $2012 \mathrm{~m}$ ) of GT-2. The pressure applied to grow the fracture equals approximately $2250 \mathrm{psi}$ (157.5 bars) above the hydrostatic pressure. After extending the crack for $8.5 \mathrm{~min}$ at a flow rate of $25 \mathrm{gal} / \mathrm{min}$ ( 94.61 iters $/ \mathrm{min}$ ), the fracture was vented immediately and yielded 72.4 gal (274 11ters) of return flow within $2 \mathrm{~min}$, whereby the overpressure observed at the surface decayed to approximately 261 psi (18 bars). We assume that the recovered amount, after being corrected for decompressional effects in the pressure line, represents roughly the portion of the water which existed in the fracture prior to venting.

To describe mathematically the total amount of fluid lost from the fracture into the rock through any given area, we define as follows:

The time between the onset of fracture initiation $(t=0)$ and venting of the crack $\left(t=t_{t}\right)$ will be divided in a time steps, dt.

$d t=\frac{t}{a}$ 


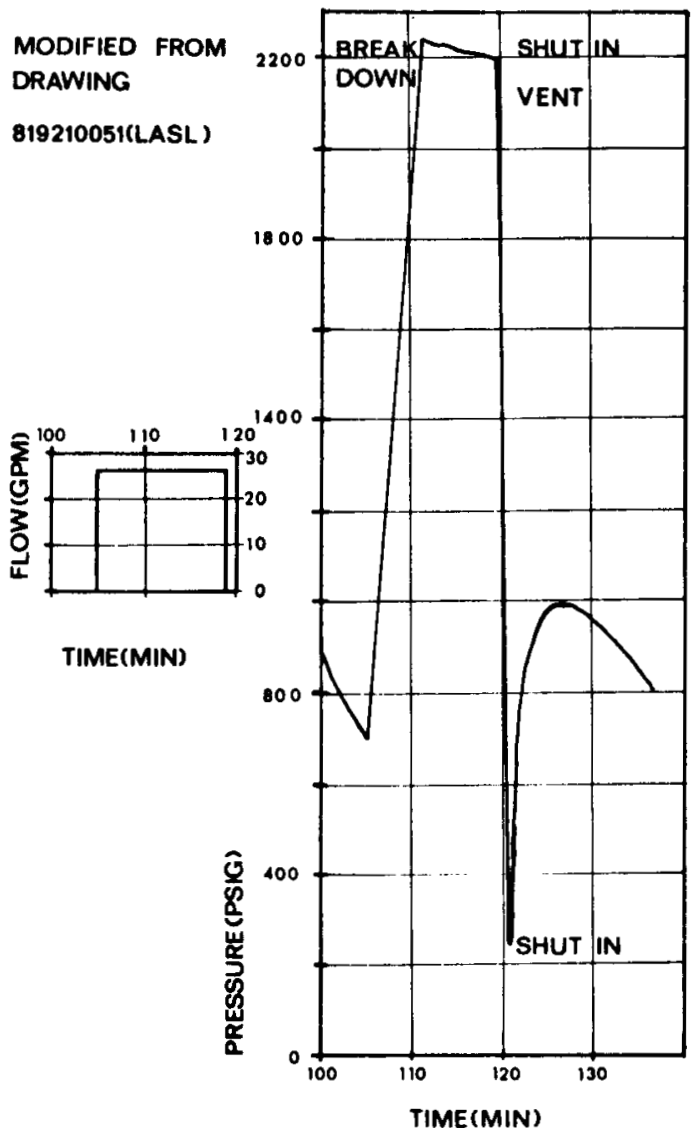

Fig. 1. Pressure and flow history for a hydraulically fractured region of $\mathrm{GT}-2$ (Zone 7 , 6500 to $6701 \mathrm{ft}$ [1981 to $2042 \mathrm{~m}])$.

Then

$Q=2 \sum_{n=1}^{a} A_{n} \int_{0}^{t} v_{n}(t) d t \quad 1 \leq n \leq a$

where $A_{n}$ is the area generated at time $n d t$ and $v_{n}(t)$ is the penetration rate of water at the interface $x=0$ for the given area $A_{n}$,

$A_{n}=5.74 \times 10^{5} \pi\left(\left(\frac{Q_{r} n d t}{37.85}\right)^{0.8}-\left(\frac{Q_{r}(n-1) d t}{37.85}\right)^{0.8}\right)$.

The total amount of water penetrating the rock then amounts to

$$
\begin{aligned}
& Q=2 \sum_{n=1}^{a} 5.74 \times 10^{5} \pi\left(\frac{Q_{r}}{37.85}\right)^{0.8} \\
& \quad \times\left((n d t)^{0.8}-((n-1) d t) 0.8\right) \int_{0}^{t^{t}-n d t} v_{n}(t) d t ;
\end{aligned}
$$

and by rearranging,

$$
\begin{aligned}
\mathrm{Q}=2 \sum_{n=1}^{a} 5.74 \times 10^{5} \pi\left(\frac{\mathrm{Q}_{\mathrm{r}}}{37.85}\right)^{0.8} \frac{\Delta \mathrm{P} \sqrt{\mathrm{c} \phi \mathrm{k}}}{\sqrt{\mu \pi}} \\
\quad \times \sum_{n=1}^{a}\left(\left(\frac{n \mathrm{t} t}{a}\right)^{0.8}-\left(\frac{(n-1) \mathrm{t} t}{a}\right)^{0.8}\right) \int_{0}^{\mathrm{t}} \frac{\mathrm{t}^{-n d t}}{\sqrt{\mathrm{t}} \mathrm{dt} ;}
\end{aligned}
$$

which can be simplifled to

$$
\begin{aligned}
Q & =4 \times 5.74 \times 10^{5} \pi\left(\frac{Q_{r}}{37.85}\right)^{0.8} \frac{\Delta \mathrm{P} \sqrt{\mathrm{c} \phi \mathrm{k}}}{\sqrt{\mu \pi}}\left(\frac{{ }_{t}}{a}\right)^{0.8} \sqrt{\mathrm{t}_{\mathrm{t}}} \\
& \times \sum_{n=1}^{a}\left(n^{0.8}-(n-1)^{0.8}\right)\left(1-\frac{n}{a}\right)^{1 / 2} .
\end{aligned}
$$

The value of $Q_{r}$ is somewhat time dependent as

$Q_{r}=Q_{r_{i}}-\frac{\Delta P \sqrt{\phi c k a}}{\sqrt{\mu \pi t}} \sum_{i=1}^{n} \frac{A_{i}}{\sqrt{i}}$

$Q_{r_{i}}=$ initial flow rate.

The value of the summation expression increases after a short period of time very slowly, $Q_{r}$ stays in essence constant and, on the average, equals

$Q_{r} \simeq \frac{Q \text { injected }-Q \text { lost into rock }}{t_{t}},[1$ iters $/ \mathrm{sec}]$.

Since the total fracture area $A_{t}$ is given by,

$A_{t}=5.74 \times 10^{5} \pi\left(\frac{Q_{r} t_{t}}{37.85}\right)^{0.8} \quad\left[\mathrm{~cm}^{2}\right]$ 


$$
\begin{aligned}
Q= & \frac{4 A_{t} \Delta \mathrm{P} \sqrt{\mathrm{c} \phi k t_{t}}}{\sqrt{\mu \pi}}\left(\frac{1}{a}\right)^{0.8} \\
& \times\left(\sum_{n=1}^{a} \cdot\left(n^{0.8}-(n-1)^{0.8}\right)\left(1-\frac{n}{a}\right)^{1 / 2}\right) .
\end{aligned}
$$

The series

$$
\frac{1}{a^{0.8}} \sum_{n=1}^{a}\left(n^{0.8}-(n-1)^{0.8}\right)\left(1-\frac{n}{a}\right)^{1 / 2}
$$

can be shown to be convergent and to approach the value 0.70747 as $a+\infty$. The permeability of the rock adjacent to the fracture can now be evaluated from $\mathrm{Eq} \cdot(8)$.

$k=\left(\frac{Q \sqrt{\mu \pi}}{4 \mathrm{~A}_{\mathrm{t}} \Delta \mathrm{P} \sqrt{\mathrm{c} \phi \mathrm{t}_{\mathrm{t}}} 0.70747}\right)^{2}$.

Equation (9) can be applied to evaluate the in situ permeability of the granitic rock section in zone 7 of GT-2 from experiment GT-2-7-258 (see also Fig. 1). In the time interval of 106 to 118.5 min after the beginning of the experiment, a total of $300 \mathrm{gal}$ (1136 liters) was injected into the borehole. In the first $4 \mathrm{~min}, 100 \mathrm{gal}$ (379 liters) of water flowed into the borehole with no fracture presenc. Thirty-two gal (121 1iters) of this amount can be attributed to the compression of the water column in the pipe string. Sixty-eight gal (258 liters) were lost into the side walls of the open hole and possibly by leaking. During fracture propagation, a comparable amount of water loss must be expected. Then the total quantity of fluid injected into the fracture amounts to $300 \mathrm{gal}-2.13 \times 68 \mathrm{gal}-32 \mathrm{gal}=123.5$ gal (467 liters). After venting, $72 \mathrm{gal}$ (273 liters) have been recovered. Since 32 gal (121 liters) must be attributed to the decompression of the water column, a maximum of 40 gal (151 liters) could have originated from the fracture. From these data, the permeability of the rock can be calculated using consistent units to amount to $4.1 \times 10^{-6}$ darcy $(\mu=$ $0.0002 \mathrm{~Pa}-\mathrm{sec}, c \phi=3 \times 10^{-11} \mathrm{~Pa}^{-1}, \mathrm{t}_{\mathrm{t}}=510 \mathrm{sec}$, $\Delta \mathrm{P}=20.5 \mathrm{MPa}, \mathrm{A}_{\mathrm{t}}=5.455 \times 10^{2} \mathrm{~m}^{2}$ for $\mathrm{Q}_{\mathrm{r}} \mathrm{t}_{\mathrm{t}}=151$ liters, and $\left.Q=0.316 \mathrm{~m}^{3}\right)$.

\section{DISCUSSION}

The calculated permeability is in close agreement with reported values ranging from several microdarcys to a fraction of a microdarcy, derived independently by other means from closeby rock sections in GT-2. ${ }^{4,5}$ Nevertheless, the proposed mathematical model needs further refinement, especially in the determination of the amount of fluid rejected from the fracture upon venting. It might prove useful to determine the time of fracture closure from seismic data or from the termination of the natural oscillation of the fracture during venting. Alternatively, an accurate determination of the return flow of water after venting should reveal changing flow rates with time, which can be attributed to the decompression of the water column in the pressure line, the return flow of water from the fracture, and finally, from the rock itself. From these data, an accurate estimation of the amount of fluid rejected from the fracture w11l be obtainable after correcting for the effects of decompression and pore fluid flow.

The above model may prove to be one of several ways to confirm the validity of the concepts by which the total area of a created fracture is calculated. Any large deviation of the calculated area $A_{t}$ from the actual surface area of the crack should cause Eq. (9) to yield values of $k$ which are in serious disagreement with values obtained by other methods, (i.e., by measurement of $k$ in the laboratory on core samples).

\section{CONCLUSION}

The granitic rocks penetrated by GT-2 and subjected to hydraulic fracturing were found to possess permeabilities in the microdarcy range.

\section{ACKNOWLEDGMENTS}

I would like to thank the Energy Research and Development Administration and the Los Alamos Scientific Laboratory for their generous invitation to participate in the ongoing research activities concerning the dry hot rock technology. I am indebted to J. W. Tester for his careful review of the paper and refinement of the mathematical portion. Furthermore, I would like to extend my thanks to the Group Leader, M. C. Smith, and a11 members of Q-22 for their friendly guidance in acquainting me with all of the scientific aspects of the dry hot rock concept. 


\section{REFERENCES}

1. I. N. Sneddon, and A. A. Elliott, "The Distribution of Stress in the Neighbourhood of a Crack in an Elastic Solid," Proc. Roy. Soc. Lond on A187, 229-260 (1946).

2. R. A. Sack, "Extension of Griffith's Theory of Rupture to Three Dimensions," Proc. Phys. Soc. London 58, 729-736 (1946).

3. R. L. Aamodt, Los Alamos Scientific Laboratory, personal communication, June 1975
4. M. C. Smith, R. L. Aamodt, R. M. Potter, and D. W. Brown, "Man-Made Geothermal Reservoirs," Proc. Second United Nations Geothermal Symposium, San Franc1sco, CA, May 19-29, 1975.

5. F. G. West, "Hydrology," Proceedings of the NATO-CCMS Information Meeting on Dry Hot Rock Geothermal Energy, September 17-19, 1974, Los Alamos Scientific Laboratory report LA-5818-C, NATO CCMS report No. 38 (December 1974). 